\title{
The uncomfortable bedfellows of health care and business
}

\author{
Stephen Hancocks OBE \\ Editor-in-Chief
}

There is a central paradox about the way in which health care and business come together - or don't. On the one hand there is a broad consensus that health is a human right. Similarly, therefore, it is reasonable to assume that access to appropriate health care is also a right and so by default is either free, or at least affordable. The difficulty that immediately arises is one of definitions. What do we mean exactly by health? Is it merely the absence of disease, or is it a wider measure of well being; physical, psychological and spiritual? What is appropriate? What is free? What is affordable?

On the other hand there are people who need to make their living from the profession to which they have committed; health care. Who provides them with their remuneration when the service they are providing is free or affordable? Are there similarities in other walks of life? Food perhaps. Isn't it also a human right to have enough food to eat and water to drink? Yet how many of us would manage to get past a supermarket checkout without paying on the basis that the trolley full of goods that we have selected was our right?

So where in all of this does a right to oral health care sit and where, as providers, do we figure? It would be a great comfort to us all if there was a single easy answer to resolve these issues, but I regret that to the best of my knowledge, there is not. Instead there is a complex maze of social expectations, cultural understandings and historical developments which coalesce to create the less than logical approach we have to the subject. Mapped onto this fractured pattern is the overriding and overwhelming argument that the two main oral diseases, the ravages of which we have to deal with, are preventable.

\section{A LONG TIME WITHOUT A MEASURE}

Ironically, for us in the UK, the question seemed more clear cut when there was far more oral disease in the population as a whole. At the beginning of the NHS, now some 60 years ago, the idea of categorising those with certain types or levels of disease and those who could or could not afford treatment was unthinkable, as caries in particular was so rife. It is salient to remember that it was not until 20 years later that the first Adult Dental Health Survey of England and Wales (1968) even began to quantify the levels of disease and enable an estimate of treatment need to be calculated.
Should it be then, that the delivery of the care required for the basic right to oral health is provided and paid for by 'society', in the form of government or state funding while anything which people, patients, desire beyond that has to be paid for by the individual? While there seems the potential for a neat logic in such an arrangement there are also problems which still arise. What about implants versus acrylic dentures, for example, which is a human right and which merely an expensive and desirable luxury? Should an adolescent whose teeth protrude but not beyond a certain defined overjet be denied free or subsidised orthodontic treatment even though his or her mental health is being jeopardised by bullying because of their appearance?

These are questions that we have been shielded from having to consider until now because the NHS has by-and-large been there for most of us for most of the time. Therefore the need to define the borders between health care and business has not been uppermost. Just 'getting on with it' has been the norm. The new situation in which many of us find ourselves for the first time is therefore slightly bewildering. Is that which we have been providing for many years been a business service and not health care after all?

Some items of treatment, or at least therapy, are more easily defined as being desirable rather than a health need. Cosmetic dentistry fits neatly here as does the modern hunger for tooth whitening. It is tempting to add scale and polish to this list but since we are told that the evidence for its effectiveness, even after so many years, is equivocal, then perhaps will we let this one go. Many treatments, however, are still uncomfortably in the grey area in between, exacerbated by the variety of options, materials and techniques that are increasingly made available to us from an industry also eager to make its living from what it similarly sees as a legitimate form of business.

The answer will almost certainly lie in the continued negotiation between provider and payer of what is deemed necessary and adequate on the one hand and that which is deemed desirable and beyond direct need on the other. If the situation seems alien to us at present, I suspect that the process is set to become far more complex before it ever has a chance of a more simple resolution.

DOI: 10.1038/bdj.2008.109 